\title{
Perception of nurses regarding risk classification in emergency care units
}

\author{
Percepção de enfermeiros sobre a classificação de risco em unidades de pronto atendimento \\ Percepción de enfermeros acerca de la clasificación de riesgo en unidades de pronta \\ atención
}

Carmen Lúcia Mottin Duro ${ }^{1}$, Maria Alice Dias da Silva Lima ${ }^{1}$, Patrícia Fátima Levandovski ${ }^{1}$, Marcia Luciane da Silva Bohn ${ }^{1}$, Kelly Piacheski de Abreu ${ }^{1}$

This study aimed to assess nurses' perception regarding the risk classification in emergency care units. It is a descriptive study that used a qualitative approach and that was conducted with 55 nurses from emergency care units in the south of Brazil. Data were collected between July and October, 2011, through open questions, answered in writing. The data collected were submitted to the thematic analysis technique. Results indicate that the risk classification contributes to the organization of the service flow provided to patients, intervening in severe cases and preventing sequelae. Difficulties were described, such as: inadequate physical installations, overcrowding, disagreement in the definition of priorities among doctors and nurses and lack of articulation between the emergency care network and basic health care. It is highlighted the need to improve the physical structure, the quantity of human resources and the implementation of public policies to overcome these challenges. Descriptors: Triage; Emergency Nursing; Emergency Medical Services.

Objetivou-se avaliar a percepção de enfermeiros sobre a classificação de risco em unidades de pronto atendimento. Estudo descritivo de abordagem qualitativa, do qual participaram 55 enfermeiros de unidades de pronto atendimento da região sul do Brasil. A coleta de dados ocorreu de julho a outubro de 2011, por meio de questões abertas, respondidas por escrito. Os dados foram submetidos à técnica de análise temática. Os resultados indicam que a classificação de risco contribui para organização do fluxo de atendimento dos usuários, intervindo nos casos graves, evitando sequelas. Foram descritas dificuldades, como instalações físicas inadequadas, superlotação, discordância na priorização dos casos entre médicos e enfermeiros e falta de articulação da rede de atenção às urgências com a atenção primária. Destaca-se a necessidade de melhorias na estrutura física, no quantitativo de recursos humanos e implementação de políticas públicas para superar esses desafios.

Descritores: Triagem; Enfermagem em Emergência; Serviços Médicos de Emergência.

El objetivo fue evaluar la percepción de enfermeros acerca de la Clasificación de Riesgo en Unidades de Pronta Atención. Estudio descriptivo, de enfoque cualitativo, del que participaron 55 enfermeros de unidades de pronta atención en el Sur del Brasil. Datos recolectados de julio a octubre de 2011, mediante preguntas abiertas, respondidas por escrito. Los datos fueron sometidos a la técnica de análisis temático. Resultados indicaron que la clasificación de riesgo contribuye a organizar el flujo de atención de pacientes, interviniendo en casos graves, evitando secuelas. Fueron descriptas dificultades, como instalaciones físicas inadecuadas, sobrecarga de las unidades, desacuerdo en la priorización de casos entre médicos y enfermeros y falta de articulación de la red de atención de urgencias con la de atención primaria. Se destaca la necesidad de mejoras en la estructura física, en la cantidad de recursos humanos, sugiriéndose implementación de políticas públicas para superar tales desafíos.

Descriptores: Triaje; Enfermería de Urgencia; Servicios Médicos de Urgencia.

\footnotetext{
${ }^{1}$ Universidade Federal do Rio Grande do Sul. Porto Alegre, RS, Brazil.

Corresponding author: Carmen Lúcia Mottin Duro

Rua São Manoel, 963 - Rio Branco, CEP: 90620-110. Porto Alegre, RS, Brazil. E-mail: carduro@gmail.com
} 


\section{Introduction}

Emergency services are an important form of access of users to a health system. In recent years, the Ministry of Health has devoted special attention to the services that provide such care, creating health care policies for the organization of the Emergency Care Network, in order to integrate health services, widen and improve access of users in emergency situations ${ }^{(1)}$.

One of the strategies adopted to organize care in emergency departments is the Risk Classification, which is based on structured triage systems. In many countries, like England, United States, Canada, among others, nurses use flowcharts for the prioritization of care, according to the needs presented by users, directing them to the appropriate care, in order to reduce the waiting time. In Brazil, the risk classification is a relatively new activity in nurses' performance ${ }^{(2)}$.

The evaluation and classification of patients' risk is guided by protocols that underlie the decision making for the definition of risks ${ }^{(2)}$. Nurses must have knowledge about the population's clinical, surgical and psychosocial conditions, because the context of an emergency department is characterized by a diversity of problems ${ }^{(3)}$. Furthermore, knowledge about the support systems of care network in the Brazilian reality, especially for referrals to other services is necessary ${ }^{(2-4)}$.

In Brazil, the implementation of the risk classification was considered as an instrument to support the performance of nurses and accelerate the service provided to users ${ }^{(2)}$. Nurses' role in the risk classification has been described as a result of the combination of theoretical and practical knowledge, involvement with public policies and the organization of the work environment, associated with the concern about welcoming of users and the humanization of care $^{(4)}$.

In international studies about the subject, authors reported that triage nurses work under pressure to assess the prioritization and to determine who can safely wait for treatment in the emergency department. The risk classification is conducted in overcrowded services, with an increasing number of users with expectations of being attended quickly ${ }^{(5)}$. Nurses deal with uncertainty and often receive very little information during this process. This implies high demands, because it is expected that these professionals are able to quickly make decisions that, if inadequate, can lead to permanent injury or death ${ }^{(6)}$.

In emergency care units, nurses experience conflicts and difficulties in the operationalization of risk classification, whose conflicting interactions are established according to the discontent of patients when there is no agreement regarding the prioritization of care determined during the risk classification ${ }^{(7)}$. Regarding the difficulties, it is highlighted the increased workload for professionals who perform this activity, generated by the large flow of patients looking for care and the lack of reference and counter reference systems, which causes the accumulation of patients and overcrowding of services $^{(8)}$. The lack of physical structure was also indicated by nurses as one of the weaknesses of the risk classification ${ }^{(8-9)}$.

Although it is an activity full of challenges, few studies assess nurses' perceptions. Thus, discussion about their perceptions regarding these activities may provide a basis for qualifying the management and care in emergency departments. Thus, this article aims to evaluate nurses' perceptions about the risk classification in emergency care units.

\section{Method}

This is a descriptive exploratory study with a qualitative approach, connected to the project entitled "Structuring of the health services network in the city of Porto Alegre to attend urgent situations", whose objective is to analyze the organization of services in the attention to urgent situations, besides identifying the working process developed in the services that compose this network.

An emergency care unit represents one of 
the components of the Emergency Care Network that provides assistance to users of intermediate complexity affected by acute and chronic conditions that have worsened dramatically. These services are responsible for receiving users and making interventions in their health problems, enabling a full resolution and, if necessary, redirecting them to another service, according to the complexity of the care required ${ }^{(1)}$.

The participants were nurses from emergency care units from a city in the south of Brazil. For the selection of nurses, as an inclusion criterion their experience in risk classification was considered. Nurses on vacation, those who were on leave and who did not accept to be part of the study were excluded.

Data collection was performed from the period of July to October 2011 through a questionnaire with questions that were answered in writing. The following questions were elaborated, taking into consideration aspects pointed out in the literature about the subject: Does the risk classification contribute to the organization of emergency services? In what way(s)? Are there difficulties in implementing a risk classification by nurses? What are they?

The information obtained from the responses were subjected to content analysis, of the thematic analysis type, which consists of three steps: Preanalysis, material exploration and processing of data obtained, inference and interpretation. During the pre-analysis, there was a brief reading and organization of the material, in order to grasp the main ideas and important aspects. Thereafter, the exploration of the material was held, with grouping of data in nuclei of understanding and coding of the text, ie, the systematization of specific themes related to the characteristics of the content. Finally, the treatment, inference and interpretation of the results were conducted, through the relationship between the structured empirical material and the literature ${ }^{(10)}$.

The sample consisted of 55 nurses from four emergency care units, named A, B, C and D, being 24 from A, 10 from B, 15 from C and 6 from D. Participants were coded with letters and numbers, respectively NUR1 to NUR55. This acronym was used to abbreviate the word "nurse" followed by the numbering sequence from the data collection.

Ethical principles were respected as determined by the national resolution on ethics in research involving human beings, whose registry on the Ethics Committee in Research was done under No. 498, Case number 001.020247.10.9.

\section{Results}

Regarding the nurses' characterization, 58.2\% had exercised the profession for over ten years. The average working time was approximately three years.

Concerning the time spent working in emergency units, $34.5 \%$ had worked for one year; $32.8 \%$ had worked in emergency care units for over 10 years.

The sectors with nurses' performance were, respectively, observation rooms of adults, children and risk classification. Taking into account the recent implementation of risk classification in emergency units, a significant participation of nurses developing this activity was found.

The results were presented according to the following thematic categories: Contribution of the Risk Classification in nurses' perception and Nurses' difficulties to perform the risk classification.

\section{Contribution of risk classification in nurses' perception}

Due to the need of organizing care, nurses highlighted that the risk classification promotes improvements in the managing of the users' admission, and it also enables the prioritization of attendance of those with potential risk of harm in the Emergency Care Units, as evidenced below: Organizing in a way so that patients with higher severity are attended before the ones with less complicated cases (NUR5). Prioritization of emergencies; work organization of the health team; patients' calmness (NUR7). 
Furthermore, it was identified that the risk classification establishes a forecasting service for users: With the risk classification, the urgency/emergency care is prioritized. Patients are assessed and receive a time estimate for being attended. The parameters set out in the risk classification protocols standardize and provide greater security for the evaluation performed (NUR25).

Nurses were unanimous when they stated that the risk classification ensures attendance in emergency care services and it is essential for their security and to determine the seriousness of the users' situations and their allocation at the correct level of care. The prioritization of needs was highlighted, which decreases the risk of worsening and sequelae resulting from prolonged waiting time: Setting priorities among health cases. Preventing serious cases from waiting longer than necessary (NUR21). It prioritizes care, thus preventing life risky situations and sequelae due to a delay of the attendance (NUR44).

In Emergency Care Units, nurses have provided guidance about the services of the health care network, because they understand that the risk classification helps to clarify users with non-urgent grievances about the service where they should look for attendance: Orientation and guidance of non-urgent cases (NUR32). Due to the possibility of evaluating cases that require emergency care (acute) and others that need other kinds of attention (NUR52).

One of the concerns nurses have is to guarantee access of all users, providing attendance in a way that avoids exclusionary practices: patients are treated in an equitable way, without neglecting anyone, but each patient waits an amount of time compatible with his need (NUR47).

After the recognition of the users' needs, evidenced by the assessment, nurses highlighted the importance of welcoming during risk classification: It allows patients to be welcomed and seen as a whole (NUR37). Humanizing nurses' work and ensuring attendance according to their needs (NUR8).

Nurses understand that this proposal contributes to rearrange users' attendance, through listening and solving of their health problems and the provision of care. However, they pointed out difficulties in carrying out this activity.

\section{Nurses' difficulties to perform risk classification}

Among the difficulties reported, there is the inadequacy of the physical area of emergency care units to perform the risk classification, considering the needs of nurses and users: It is necessary (there should be) a room reserved for the interview without interruptions (NUR17). Tumultuous physical area, little privacy and security (NUR35).

According to the nurses, the existence of appropriate environment is essential to the conduction of risk classification, since users need to present their complaints and, from them, information about their health status are collected, such as previous diseases, signs and symptoms. Inadequate physical structure of the emergency care units harms privacy.

Even with the inadequacies of physical space, nurses perform a significant number of attendances of risk classification due to the large demand from users. They reported that many of the evaluated situations are possible to be attended in services of smaller complexity, available in the health care network: The great demand of cases (that arrive at the emergency care unit) that could be attended in basic health units is the main difficulty (NUR25). Patients sent from basic health units with problems that could have been resolved there (NUR5). The number of patients that look for the emergency care unit is very large, and most of them have problems that could be solved in the basic health network (NUR20).

They also indicated that there is a poor coordination between the attendance of users in the emergency care unit and the assistance in the basic health units: The difficulty is to send patients to the basic health units [non-urgent cases] (NUR6).

Nurses report that the attendances of a high number of users with clinical features considered not urgent, produces increased waiting time for medical consultations and contributes to the service's overcrowding. Overcrowding, in turn, generates anxiety in users who look for information about their attendance, so nurses have to inform users about the criteria of risk classification, becoming an exhausting 
activity throughout their work shift: (The) patients look for the emergency care unit. This generates a longer waiting time for consultations, which stresses the population out and consequently the nursing staff too (NUR32). Stable patients get angry because they have to wait for their consultations, which sometimes takes up to 6 hours (NUR43). Patients don't understand the risk classification and get angry when others cut in line (NUR41).

The lack of understanding of the population about the risk classification was mentioned as a difficulty in the care management. In nurses' opinion, prioritization is a way of organizing access to immediate care, because previously, in most services, admission occurred through the order of arrival.

The working conditions do not favor assistance to a high number of users, since human and material resources are insufficient and inadequate: Lack of human resources, equipment and materials which are appropriate and working properly (NUR55). More patients than the amount of available consultations (NUR23).

Difficulties of the medical staff to accept the prioritization of users were described by nurses: Resistance of doctors to attend the ones we prioritize. The problem is with the medical staff, they do not understand the prioritization (NUR47). Difficulties with the medical staff, who sometimes do not agree with the criteria for prioritization (NUR46).

Nurses highlight that the medical staff do not agree with the criteria adopted for the risk classification. Moreover, the insertion of nurses in this activity is recent in Emergency Care Units, and after the implementation of this device, changes occurred in the work organization of the staff that works in these services.

\section{Discussion}

Nurses consider that the purpose of risk classification is to prioritize the attendance to users with potential risk of harm and the appropriate use of the available resources, according to the severity of their clinical conditions. This result corroborates the findings of other authors, who claim that the risk classification contributes positively to the organization and prioritization of care ${ }^{(8,11)}$. Another study confirms that the risk classification provides a faster response to users with acute illnesses that require immediate intervention. In this sense, it contributes to the safety of nurses in the assessment and it provides advances in the quality of care, becoming an instrument of work organization $^{(8)}$.

It was highlighted that the risk classification provides safety to users with potentially urgent clinical conditions. In agreement with this finding, a study conducted concluded that the triage system is essential for patients' safety and is a prerequisite for the rapid identification of the seriousness of the users' situation and their allocation in the correct level of care $^{(12)}$.

Nurses have played a key role concerning guidance to users. A similar result was observed in the northeast region, in Fortaleza, Ceará, in which one highlighted that users give importance to nurses due to the information they provide about the risk classification. Professionals indicated that the risk classification favors users' orientation about the services available within the health system and the probable waiting time in the emergency care unit ${ }^{(13)}$. This behavior was also observed in another study in which it was highlighted that the levels of health care should form a network of resources with previous pacts, so that a service complements the actions of the other, aiming at improving the quality of care ${ }^{(8)}$.

It was a nurses' concern the warranty of attendance for users who look for the emergency care unit. All emergency services should ensure universal access, welcoming and listening to the health problems of the population in order to try to solve them. The literature highlights that nurses worry about factors that involve not only the act of risk classification, but also with patients' welcoming as a whole ${ }^{(11)}$. However, another study demonstrated that the understanding of nurses about the risk classification was limited to focus on prioritizing the risk of clinical condition, without being connected to the users' needs ${ }^{(9)}$. This perception may be the result of the organization of 
services, which is still based on the biomedical model that favors the production of procedures and activities, rather than the use of relational and communication skills in order to welcome users at a moment when they are very vulnerable. In this study, the welcoming of users was remembered by the participants, as being present in the risk classification.

Regarding the difficulties to perform the risk classification, according to the perception of nurses, it is high the number of users who have medical conditions that could be attended by less complex services available in the health care network. However, in contrast, the study indicates that health services that are considered of medium complexity should be open to the demands from the primary health care, having as a mission to perform actions that have resolution, avoiding the worsening of clinical situations. The emergency care unit is considered a space that provides assistance in conditions not provided by the primary health care ${ }^{(14)}$. Among the challenges, it was highlighted that the services of primary health care do not favor the access to the users, which, in turn, seek the emergency care unit as an opportunity to resolve their problems, even if they are not an urgent case or an emergency ${ }^{(14)}$.

Another aspect mentioned by nurses is related to the poor coordination between the emergency care units and the primary health care, which complicates the guidance of non-urgent users who seek care in the emergency care services. The Brazilian health system is organized in a fragmented way, and the primary health care does not communicate properly with the health services at a secondary level and these two levels also do not communicate with the tertiary health care. The implementation of attention networks among the services would enable communication among other network points, because if they are isolated, they are unable to provide continuous attention to the population $^{(15)}$.

It is considered that users must have their health needs attended, even if they are expressed through the use of services of advanced technology for non-urgent health problems. However, users would also be able to use other health services available in the network, since they would benefit from this assistance, considering that many users have health needs that require ongoing treatment, available in the primary health care. However, it is recognized that the attendance to users with non-urgent or less severe clinical conditions contribute to overcrowding of emergency care units, causing longer waiting periods for care, resulting in excessive workload and physical tiredness for the health teams.

Similarly, it was found that the indiscriminate access to emergency services causes tension in places where the service is done, resulting in wear for workers and discomfort for users ${ }^{(15)}$. Furthermore, the insufficient number of nurses to attend the demand, as well as the inadequacy of equipment and the physical area of the emergency care units are factors that increase the wear of the teams that perform risk classification. Corroborating these findings, it was identified that the professionals' stress was related to the workload caused by the deficit of resources and excessive number of users seeking assistance in those units $^{(16)}$.

The lack of understanding of the population about the risk classification was reported by nurses as a factor that hinders this activity. For users, their health problems need immediate care, while for nurses, the priority of care is done in accordance with the gravity of the situation presented. The divergence of views among users and nurses about the risk classification generates conflicts and criticisms of the service and professionals. Consequently, there is also a lack of understanding of users when they are evaluated, admitted and sent to other places, creating aggression and disrespect ${ }^{(7)}$. Another survey, conducted in an emergency care unit found that the performance of risk classification is a stressful activity due to its difficulties in the organizational functioning of the service and to the violence on the part of users and companions ${ }^{(16)}$.

The difficulty of the medical staff to accept the 
prioritization of risk assigned by nurses was reported by participants as a barrier to the development of the risk classification. This form of organization has created changes in the teamwork, because the type of interdisciplinary attendance, with contributions of each team member, became essential to the success of the process $^{(9)}$. The changes in the users' admissions, organized by nurses, might have created resistance from doctors to accept this techno-assistanceorganizational device. In the risk classification, doctors sometimes do not agree with nurses on the attribution of priorities, resulting in conflicting relationships, since this activity can pose a threat to the prevailing medical hegemony in services health.

\section{Conclusion}

The findings of this study contribute to the understanding of nurses' perception about the risk classification and it can foster reflection about the aspects listed in order to improve the attendance provided to users in emergency care units.

From nurses' perception, it can be inferred that the risk classification contributes to the service organization and it is essential for the organization of the inflow of attendances in emergency care units. The results enable one to conclude that the risk classification optimizes access and provides security for users, as the evaluation and prioritization of care allows interventions more effectively, avoiding injuries and sequelae.

It was found that the main challenges in the risk classification are: precariousness of physical facilities, overcrowded units, the search of the service by users in non-urgent medical conditions, disagreement in the prioritization of cases between doctors and nurses and the lack of connection of the emergency care network with the primary health care.

To remedy these difficulties there is the need to improve the physical structure and quantity of human resources, in order to promote the success of the proposed risk classification and enhance the care provided. Furthermore, it is imperative the development of public policies that ensure integration between the emergency care units with other services of attention from the emergency network.

As limitations of this study, one highlights the exclusion of other professionals who are involved in the risk classification, since this action triggers the care provided by other health professionals. In addition, some information may have been omitted by the participants during the data collection, which did not involve interaction and face to face communication between participants and researchers.

\section{Acknowledgements}

To the National Council for Scientific and Technological Development for the financial support through the process No. 478895/2008-9.

\section{Collaborations}

Duro CLM, Lima MADS, Levandovski PF, Bohn MLS and Abreu KP contributed to the creation of the study, data collection, analysis, interpretation of data, drafting of the article and final approval of the version to be published.

\section{References}

1. Ministério da Saúde (BR). Portaria 1600 de 07 de julho de 2011. Reformula a Política Nacional de Atenção às Urgências e institui a Rede de Atenção às Urgências do Sistema Único de Saúde. [Internet] [citado 2014 Jan 13]. Disponível em: http:// bvsms.saude.gov.br/bvs/saudelegis/gm/2011/ prt1600_07_07_2011.html

2. Souza CC, Toledo AD, Tadeu LFR, Chianca TCM. Risk classification in an emergency room: agreement level between a Brazilian institutional and the Manchester Protocol. Rev Latino-Am Enfermagem. 2011; 19(1):26-33.

3. Fitzgerald G, Jelinek GA, Scott D, Gerdtz MF. Emergency department triage revisited. Emerg 
Med J. 2010; 27(2):86-92.

4. Shiroma LMB, Pires DEP. Classificação de risco em emergência - um desafio para as/os enfermeiras/ os. Enferm Foco. 2011; 2(1):14-7.

5. Foley A, Durant J. Let's ask that out front: health and safety screenings in triage. J Emerg Nurs. 2011; 37(5):515-6.

6. Forsgren S, Forsman B, Carlström ED. Working with Manchester triage: job satisfaction in nursing. Int Emerg Nurs. 2009; 17(4):226-32.

7. Zanellatto DM, Dal Pai D. Práticas de acolhimento no serviço de emergência: a perspectiva dos profissionais de enfermagem. Ciênc Cuid Saúde. 2010; 9(2):358-65.

8. Nascimento ERP, Hilsendeger BR, Neth C, Belaver GM, Bertoncello KCG. Classificiação de risco na emergência: avaliação da equipe de enfermagem. Rev Enferm UERJ. 2011; 19(1):84-8.

9. Zem KKS, Montezeli JH, Peres AM. Acolhimento com classificação de risco: concepção de enfermeiros de um pronto socorro. Rev Rene. 2012; 13(4):899-908.

10. Bardin L. Análise de conteúdo. Lisboa: Edições 70; 2011.
11. Gehlen GC, Lima MADS. Nursing work in care practice at Emergency Care Units in Porto Alegre/ RS. Inv Educ Enferm. 2013; 31(1):26-35.

12. Göransson KE, Von Rosen A. Patient experience of the triage encounter in a Swedish emergency department. Int Emerg Nurs. 2010; 18(1):36-40.

13. Guedes MVC, Henriques ACPT, Lima MMN. Acolhimento em um serviço de emergência: percepção dos usuários. Rev Bras Enferm. 2013; 66(1):31-7.

14. Randow RMV, Brito MJM, Silva KL, Andrade AM, Caçador BS, Siman AG. Articulação com Atenção Primária à Saúde de gerentes de Unidade de Pronto-Atendimento. Rev Rene. 2011; 12(n. esp):904-12.

15. Dal Pai D, Lautert L. Sofrimento no trabalho de enfermagem: reflexos do "discurso vazio" no acolhimento com classificação de risco. Esc Anna Nery. 2011; 15(3):524-30.

16. Calderero ARL, Miasso AI, Corradi-Webster CM. Estresse e estratégias de enfrentamento em um equipe de enfermagem de Pronto Atendimento. Rev Eletr Enf. [periódico na Internet]. 2008 10(1):51-62. Disponível em: http://www.fen.ufg. br/revista/v10/n1/pdf/v10n1a05.pdf 